Lofmark, A., Morberg, A., Ohlund, L.S., \& Ilicki, J. (2009). Supervising mentors' lived experience on supervision in teaching, nursing and social care education. A participation-oriented phenomenological study. Higher Education, 57, 107-123.

Mose, M., Bull, R., et al. (2006). Pharmacists' views of preceptorship. Pharmacy Edtication, G(4), 245-252.

preceptorship. Pharmacy Edwon, M., Bull, R. Galbraith, K., Howarth, H., et al. (2005). Australian Marriott, J., Taylor, S., Simpson, M., Bull, R., Galbraith, K., Howarth, H., et al. (2005). Australian national strategy for pharmacy preceptor education and support. Australlan Journal of Rural Health $13,83-90$.

McAllister, L., Higgs, J., \& Smith, D, (2008). Facing and manag Higher Edication Research \& Development, 27(1), 1-13.

Molodysky, E (2007). Clinical teacher trining - maximising the "ad hoc" teaching encounter. Australian Family Physician, 36(12), 1044-1046.

Pan 14th Pacific Rim Real Estate Society Annual Conference, Kuala Lumpur, January.

14th Pacific Rim Real Estate Society Annual Conference, Kuala Lumpur, January. Schon, D.A. (1983). The reflective practitioner: How professionals think in action. New York: Basic Books.

Sclton, D.A. (1987). Educating the reflective practitioner: Towards a new design for teaching and learning in the professions. San Francisco: Josscy-Bass.

Simpon Marioll, J.L., Taylor, S., Bull, R., Howarth, H., et al. (2006). Development a of Pharmacy Practice and Research, 36, 119-121.

of Pharmacy Practice and Research, 36,
Specrs, A., \& Strzyzewski, N. (2004). Preceptor preparation: An investment in the future. Journal of Nursing Staff Development, 20(3), 127-133.

Taylor, S., Best, D., Marriott, J., Dalton, L., Dalton, R., Galbraith, K., et al. (2006). Plarmacy student views on preceptorship during rural placements. Pharmacy Edication, 6(4), 253-266.

Stephen Loftus PhD

The Education for Practice Institute

Charles Sturt University, Australia

Maree Donna Simpson PhD

School of Pharmacy

Charles Sturt University, Australia

\section{ASSESSMENT FOR DEVELOPING PRACTICE}

In professional courses assessment is typically used to ensure competence. Professional associations, wishing to ensure that graduates are safe and capable practitioners, ready for practice, often oversee it. Preparing students for continuing development as professionals may be of lesser consideration. Assessment then becomes assessment of learning, rather than assessment for learning. A narrow sense of competence focuses on technical knowledge, skills and particular limited features of professional practice. What students might require as learners to further develop their practice is subjugated to specific, easily measured competences. Ensuring readiness for practice, however, involves more than checking that graduating students possess the knowledge and skills needed to begin practice. If assessment is only about ensuring competence, then it is not about addressing the continuing needs of practice. This irony is at the heart of considerations of assessment for future practice.

In this chapter I argue that assessment should be oriented towards developing practice, even when the particularities of practice and the specific contexts for practice are not known. Indeed, a future-orientation is especially required when the specific demands of practice are unknown and unknowable. Assessment needs to do more than certify; it also has an essential educational role that, if neglected, means that students are not prepared for the uncertainties they face. The emphasis needs to be on the processes of acquisition of knowledge and skills and how learners can develop their own capabilities and those of others. Such an orientation has profound implications for the way assessment in higher education is conducted, both in initial and continuing professional education. This chapter focuses on one aspect necessary for such an orientation, the shift of assessment tasks in professional education. It considers the basic ideas needed for an orientation of assessment towards future needs and it discusses the development of a particular kind of resource-represented in a website-designed to provide ideas and strategies for university teachers to build assessment to develop the practice of their students within and beyond university courses. In doing so it outlines the decisions made to identify what would and would not be appropriate to include and the structure of the recommended assessment elements. It reflects on the conceptual basis of the resource and identifies key points of focus in creating assessment for developing practice.

\section{WHY EMPHASISE PRACTICE?}

Conventionally, assessment focuses on testing what is taught. It gives priority to knowledge and skills acquired through instruction. The major shift towards an

J. Higgs et al., (eds.), Education for Future Practice, 25l-262

O 2010 Sense Publishers. All rights reserved. 
emphasis on competence in professional areas has drawn attention to the need to focus not on what is taught, nor even what is learned, but what a student can do. Ultimately important in a competency framework is how teaching and learning are Ultimately important in a competency framework is how teaching and learning are transformed into performance. In some areas, such as vocational education and training, this view has de-emphasised teaching and pedagogy, placing competency training, this vers to transform assessment in higher education, even where competencies are framed more holistically than in vocational education and training.

Competency assessment alone, however, is only one step towards preparing Competo developstudents to continue to develop their capabilities over time. Studies of the development of expertise (e.g. Dreyfus \& Dreyfus, 2005) show that formal education and training only enable the development of early stages of expertise and that high training onle eccurs over many years. We therefore need a view of assessmen level competence occurs over man that does more than provide a snapshot of performance at a given point of time, but contributes to the development of expertise in learning for practice. Such a view of contributes to the developm issues about how it is conducted.

\section{From what has this Approach Emerged?}

There has been rapid development of concern about the impact of assessment on learning. Following Black and Wiliam (1998), there has been progressive rejection of ideas of assessment as a measuring device and a flourishing of ideas about how of ideas of assessment assessment can positively influence processes of learning (Yorke, 2003 ). Assessming. is increasingly seen as a trom Kong (Carless, Joughin, \& Liu, 2006) and assessment for employability from the UK (Knight \& Yorke, 2003).

Assessment cannot be seen solely as a necessary artefact of teaching and learning Astivities that contribute to in schools and universities learning (Boud \& Falchikov, 2006). Students need to develop skills to judge lifelong learning (Boud \& Falchilov, 2006) their own work if they are to practise responsibly following graduation. Assessment is not only something done to students but a necessary process in which they need to develop expertise if they are to continue learning throughout their careers. Assessment develop expertise if they are to coployed skilfully by students should thus be seen as an integral tool for learning, to be deployed shoughout life.

To position assessment effectively for this purpose, it is helpfully seen through the frame of practice, regarding assessment is an educational practice in its own right the frame of practice, regarding assessment is an educational proctice in its own right as well as an activity contributing to and informed by professional practice (Boud, 2009). From such a perspective we can view learning apart from the artefacts of 20urses and locate it in the world in which practice has meaning and significance. It courses and locate it in the wat constitutes good assessment. also means that we have new ways of identifying what constitutes good assessment. In this approach, assessment equips learners for practice, not by measuring their knowledge and skills but by enabling them and their teachers to determine whether kno they are making effective judgments about work. In other wis means that learners develop the capacity to effectively judge their own work. This is not a matter of adding more knowledge but of building second-order understanding that enables them to tell what knowledge and skills are needed and are being acquired. This reflexivity characterises what is needed to cope with changing knowledge and practice in the changing environments that graduates face.

Another consideration for assessment thinking is the changing nature of practice itself. Many models of professional preparation implicitly presume a sole practitioner. This, however, is not a feature of most contemporary practice, and has not been for a considerable time. Professional practice has become increasingly less individual and more collective. People operate in teams and groups, acting together with others, with responsibility for the standards of their practice and (either implicitly or explicitly) that of those around them. The notion of the autonomous professional has been circumscribed in many ways: by legislation, rules of professional bodies, codes of practice and organisational procedures. More recently, professionals have faced the even greater challenge of becoming co-practitioners with clients/customers. In these emerging forms of practice professionals do not simply provide a service, but work directly with clients in a form of co-production (Bovaird, 2007; Dunston, Lee, Boud, Brodie, \& Chiarella, 2009) in which what is produced is a joint function of what both bring to their interaction. For example, health practitioners are moving from being expert providers of advice and services to "co-producing" health with "patients" for more sustainable long-term outcomes.

In summary, this perspective positions both learning and assessment as needing to acknowledge a number of key features. These are that:

- knowledge is contextualised and located and should be recognised as such

- learners need to be reflexive if they are to be able to respond to the demands of changing knowledge and practice

- work occurs in collaboration with diverse others in many different forms

- knowledge and action are co-constructed and co-produced with fellow workers, and with others who may previously have been considered consumers of practice. The contextualised nature of knowledge production and use creates continuing tensions for university education, which, by its very nature, exists apart from the settings in which knowledge is utilised. This means that the contexts of knowledge must be recognised in courses, and repertoires of ways of dealing with them must be incorporated in assessment as well as elsewhere in the curriculum.

This leads to a notion of assessment that challenges not only measurement-driven approaches but also exclusively standards- and competency-based models. After all, if a person demonstrates meeting competency standards at a given time, especially in a supportive educational environment, this does not in itself indicate that the person can continue to meet new demands and address changing standards. Of course, it is not possible to test against standards that have yet to be identified in areas that may not yet exist. What is needed is a focus on the factors that will equip learners to develop over time.

\section{What is the Starting Point?}

Clearly, there is a need for initial education to ensure that students are equipped with skills to continue learning throughout their courses and careers. Although the 
substantive knowledge and skills required in the disciplines and professional areas underpin all practice, a focus on these alone is not enough.

In recent times universities have focused on what have been termed generic attributes or transferable skills (Hager \& Holland, 2007). These have been identified as the key competencies needed by any graduate, and typically include commuas the key sills, ability to work in a team, critical thinking, and so on. They often do not encompass the features we have been discussing here, such as learning-how to-learn skills, self-management and self-monitoring. Such meta-skills underpin both to-learn skills, self-manage generic and subject-matter knowledge and skills, but are generally not foregrounded in the generic attributes literature. It would be inappropriate to add them as additional generic attributes as they do not represent what graduates might do in the world, but rather the processes leading to what they do and how they think about what they do. However, they are certainly needed in discussions of both curriculum and assessment.

Although questions of curriculum are beyond the purpose of this chapter, if the building of learning capacity for developing practice is not built into assessment, then the skills needed for it are be promoted effectively and the message communicated to students is that they are not valued. Many aspects of this agenda are already incorporated in ongoing discussions and interactions in everyday teaching and incorporated in ongoing discussions and interactions in everyday teaching and learning. It is not, however, well articulated, nor is it sufficiently represented in
assessment tasks and the ways in which feedback is provided on the outcomes of tasks.

\section{CREATING A RESOURCE: INFLUENCING ASSESSMENT}

Conventional views of assessment that privilege measurement and certification are well entrenched in all education systems. Although much literature on assessment well entrenched in all edreaces a learning-centred and practice-oriented view (Carless et al,, 2006; Boud \& Falchikov, 2007; Joughin, 2009), such views are slow to be taken up in higher education, where teachers have little formal exposure to ideas about assessment. While most now undertake a course in Teaching and Learning in Higher Education on appointment, the time devoted to assessment matters is limited, and most will on appointment, the time devoted to assessment mate the equivalent of a single course module on the topic.

Knowledge of assessment is passed on as a folk practice, and is essentially unexamined and taken for granted. Recognition of problems with assessment may be admitted, but if the implication is change that will involve more or unde work - if more demanding assessment tasks require providing more comments on student work - then this is not an attractive prospect.

As part of a Senior Fellowship of the Australian Learning and Teaching Council during 2008-9, I developed a resource for teachers in higher education to help them design assessment for developing practice, providing a material form for the conceptualisations discussed here. The thinking that informed the design of this conceptualisations discussed here. The thinking that

The website www.assessmentfutures.com aims to focus attention on designing assessment to equip students for learning in the longer term. It adopts a particular point of view about assessment. Assessment Futures is based on the proposition that assessment in higher education has been so distorted by concerns about certification and justification that the core purposes of both higher education and assessment have been obscured (Knight, 2002). It takes the view that, whatever else it does, assessment must support learning. Further, it must support the processes of learning that students need beyond graduation. Assessment must foster attitudes and dispositions as well as the knowledge and skills that learners need for the variety of tasks they will confront throughout their lives. This means that our conception of assessment needs to encompass the idea that assessment must build students' capacity to be effective assessors for themselves and others.

Therefore, the first question to be asked of any assessment should be: Does it do what we want it to do in terms of promoting the kinds of learning that are desired for the longer term? If it doesn't, there is no point in moving to other questions, such as matters of reliability, validity or fairness.

\section{WHAT ARE THE FEATURES OF ASSESSMENT FUTURES?}

The key features of Assessment Futures are based on assumptions that require assessment to:

- contribute positively to students' learning

- take a view of what is to be learned and how it is to be learned beyond the time scale of the current course unit

- develop students' ability to make judgments about what constitutes good work

- position students as active learners

- engage students in the process of seeing themselves as people who will contribute to practice, whatever that practice might be.

Four key features frame the website's focus: the need for sustainable assessment, the requirement that assessment foster students' ability to make judgments, the desire to construct students as reflexive learners and the goal that assessment helps form dispositions for practice.

\section{Assessment should be Sustainable}

Assessment needs to meet the immediate need of providing guidance to students about their learning and about the quality of their performance in attaining learning outcomes, but it must do this without compromising the longer term aim of building their capacity to be informed judges of their own learning (Boud, 2000). Assessment that only grades or provides feedback is too limited.

Assessment tasks therefore need to look beyond the immediate situation to what is required of learners in the future. They must not cement knowledge now at the expense of what is needed later. This looking forward involves taking care to create tasks that require higher order thinking rather than "test knowledge" or lowlevel recall or analysis. Assessment tasks set benchmarks for student aspiration and must not be compromised by sending false messages about ultimate learning outcomes. 
Sustainability also involves avoiding inadvertently making students dependent on staff. This occurs when students look to pleasing the assessor at the expense of engaging their own or others' judgments of their work. Dependency is rarely planned or desired, but arises from not thinking through the consequences of any given activity and how students will interpret it.

\section{Assessment should Develop Informed Judgment}

Although all acts of assessment involve making judgments about the quality of work, if they involve only staff making the judgments, they are unlikely to build students' capacity to do this. Students must develop the capacity to make judgments about their own learning and to discern what they can and cannot do.

Summative assessment alone is too risky a strategy for any program in the contemporary complex world, as it looks back to what has been acquired, rather than forward to what is needed for new knowledge. What students need is the ability to make judgments, in concert with others, about problems and situations for which their course may not directly prepare them.

Although judgment has common features in different contexts, it is not a generic kill. It does not transfer readily from one knowledge domain to another, if at all This places it as integral to all aspects of curriculum. The development of judgment is a fundamental part of all courses, and opportunities for developing informed judgment need to be planned and staged throughout. All teaching and learning judgment need to be planned and of judgment builds over time, subject matter and different situations, opportunities are needed to exercise it throughout and across the whole program.

\section{Assessment should Construct Reflexive Learners}

To build the capacity to judge their own learning, students must be active agents. They cannot act passively as recipients of the acts of teachers. Assessment must work alongside teaching to position students to see themselves as, and to act as, learners who take responsibility for their own learning. Teaching, learning and assessment strategies that demand participation from the start strongly reinforce this process. Assessment that undermines this positioning is antithetical to the construction of students as learners.

Assessment must position students as pro-active learners and agents of their own destiny rather than conforming subjects who respond to the requirements of others. This means that they must necessarily be involved in assessment, not in the naive sense of grading themselves or choosing between assessment questions, but by establishing what constitutes appropriate standards and criteria for a given task, exercising their judgment in offering opinions of the work of peers, and constructing ways of assessing their own performance. Responding to tasks set by teachers will not fully develop the required dispositions. Practice in the construction of tasks by students is also needed. Simply adding isolated self-assessment activities, which has commonly occurred in the past (Boud, 1995), does not do this. A focus on fostering reflexivity and self-regulation is needed through every aspect of a program.
4. Assessment Needs to form the Becoming Practitioner

Whether or not a program has a vocational goal, all students who go on to be practitioners contribute to society in ways that may involve them in practices that have little or no relationship to the courses they have studied. Assessment has a central role in the formation of what we might call the becoming practitioner. To see oneself as a practitioner, not just as a student, involves a shift in identity and in ways of positioning oneself in regard to learning tasks. It needs reflexivity and a proactive orientation by the learner, rather than simply responding to the initiatives of others. A practitioner-oriented view of learning and assessment involves initiative and ownership of the tools and techniques of planning and assessment.

Practitioners must develop confidence and skills to manage and evaluate their continuing learning. As they almost always work with others they need to develop the capacity to work effectively with them to assist others' learning and to mutually develop informed judgment. Assessment needs to show not only what has not been achieved, but what has. This implies that excessively individualised approaches underpinning educational assessment should be questioned, and that students should assess and be assessed by others, collectively and individually. Students need practice in locating and engaging communities of judgment beyond themselves. These might include peers, practitioners and professional bodies, as well as other academic sources.

Finally, and most importantly, assessment needs to calibrate judgment. Learners will act on the basis of their belief in their own judgments. If these are flawed it is much more serious than having particular knowledge gaps. Assessment activities must therefore allow students to make calibrations of their judgments in comparison with the yardsticks of others. Judgments develop in specific contexts and require the context to help provide cues and standards. Judgment needs repeated application and practice over time and situations. The use of yardsticks is not a return to discredited forms of norm-based assessment; it ensures that students can have judgments of their own work tested alongside the judgments of others according to practice standards.

\section{TO WHICH ASPECTS OF ASSESSMENT DOES THIS DRAW ATTENTION?}

Assessment Futures is structured in two main categories: key elements of assessment tasks and the design and redesign of assessment activities. Most higher education teachers approach assessment with the question: what should students be asked to do? The assessment task is therefore central to planning, and encompasses specific subject matter and domain knowledge as well as the processes and academic skills needed to pursue it. Although there may be considerable planning to ensure the task is constructively aligned (Biggs, 2003), manageable and fair, efficiently marked and so on, all these considerations culminate in the task itself. The task is the tangible expression of what is valued and what most counts in a particular course or unit.

But there is much else to be decided if the task is to work well. Therefore the second main aspect is assessment design. The task must be well formulated and 
appropriate, and it must be suitably timed, communicated effectively to students, account for student prior expectations of similar tasks, and be linked to learning activities and summative assessment demands. Attention to assessment design has been relatively neglected in universities because of conventional assumptions that this kind of knowledge is picked up by example and that there is little research on which to draw. This assumption needs to be challenged. A growing body of knowledge about assessment design is now available (e.g. Boud \& Falchikov, 2007; Havnes \& McDowell, 2008; Joughin, 2009).

\section{KEY ASSESSMENT ELEMENTS}

It is useful to focus on Assessment Futures' representation of the key assessment elements, as they illustrate the kinds of activity proposed as the foundation of assessment for developing practice. At the time of writing there are eight main elements and multiple examples of types of task within each, integrating different purposes and able to do "double-duty" through addressing different requirements simultaneously (Boud, 2000).

\section{Actively Engaging Students in Learning Tasks}

This set focuses-on early and continuing engagement of students as active learners, not only in acquiring knowledge, but also in practising what they are learning. This includes seeing themselves as persons making judgments through judging others' work, identifying and developing standards and criteria. This form of participation should not be delayed until students acquire more knowledge; it is fundamental and achievable from the earliest stages.

\section{2. "Authentic" and Investigative Activities}

This group is included to provide experiences of knowledge located in the kinds of situation that might be found in practice. Rather than disaggregate knowledge and separate it from sites of application, the aim is to give a sense of context. "Authentic" is placed in inverted commas because full authenticity might be too overwhelming. Decisions must be made about how much context can realistically be included. These activities also include investigations that ask students to be knowledge generators, taking problems and issues and exploring ways in which they might be addressed This is not primarily to learn research skills but to place them as proactive learners with responsibilities to pursue agendas of their own.

\section{Students Designing Assessments}

It is commonly remarked that teachers learn more than their students. This idea is also applicable to assessment. Students gain understanding and experience through involvement in tasks requiring them to construct assessment activities, create assessment rubrics or marking schemes, and take responsibility for designing aspects of the curriculum. These activities place students in a different relationship to knowledge, more as knowledge producers than knowledge consumers (Lovitts, 2005) even at the undergraduate level (Brew, 2003). In order not to be a consumer, students need to understand how knowledge operates and is assessed as much as they need to appreciate the knowledge itself.

\section{Integrative Tasks}

The traditional university curriculum, particularly with modularised structures, separates knowledge into discrete subjects or parts. Often this is for convenience of provision and access rather for any pedagogical design considerations. There is temptation to further continue this division within units, designing discrete assessment tasks for each learning outcome. This creates simplicity of design, but it can damage the structure of knowledge and the ways in which it is used in practice. Many realworld challenges involve identifying problems and putting together knowledge in new ways. This set of activities seeks to provide situated practice for students, enabling them to take a holistic view of what they are learning through tasks of integration, within units, within the year, and across the program.

\section{Becoming Aware of Learning and Judgment}

An important part of students' development is becoming active learners who take control of their learning, and plan and monitor what they do. They are reflexive about task selection, timing and identification of what counts as "good" work, functioning as self-regulated learners (Zimmerman, 1990). The challenge of a good course is to bring out these features in all students, not just the most able. Activities in this category range from students selecting tasks appropriate to their own level of development, through to forms of self-testing and confidence marking where students' knowledge is tested and their confidence in that knowledge develops, to more complex activities where students review what they know and need to know and represent their knowledge in new forms for different purposes.

\section{Modelling and Practice}

One of the greatest difficulties students have in producing good work is discovering what it should look like. Although teachers may model good practice and can provide specific answers to questions, understanding what is good about these examples needs further activity. Engaging with model answers or worked examples is often necessary, as is extended practice in problem-solving. Commonly, assessment involves completing a task once, with little practice, and then moving to something quite different for the next. Students never see their work changing and improving over time. There is a need for staged tasks in which students have an opportunity to apply feedback to improve their work and notice that improvement has occurred. 


\section{Working with Peers}

Educational institutions misleadingly give the impression that learning and assessment are individual acts. In the world of practice this is rarely the case. Work is completed in conjunction with other people, and the ability to work with others is central to any kind of occupation. Recently there have been moves to foster teamwork and even include forms of group assessment (e.g. Li, 2001), but there is more to assessing with peers than this. The world of practice requires collaborative planning and judgment, and students need experience in practising and understanding what is involved. To help achieve this understanding students can engage in activities like peer coaching and feedback, group analyses, becoming involved not just in working on tasks together but in planning and appraising outcomes and contributionsprocesses of working out what constitutes good work and thereby judging their own activities.

\section{Giving and Receiving Feedback}

Finally, a core feature of all assessment for learning is giving and receiving feedback. Students must learn whether what they are doing is appropriate and communicates to others, and whether or not their own views correspond to the standards of others. However, feedback involves more than simply being provided with comments. Effective feedback considers the needs of the person subject to it and ensures that it is in a form that can be used. The process of giving feedback is particularly important for building capacity for further learning. Feedback is not completed by the provision of information; it requires action to apply this information to change what the recipient does, and for this to be observed by the person providing information. Teachers in higher education are collectively poor at completing the feedback loop for students, as they emphasise the provision of information rather than detecting whether their comments are taken up to improve the quality of subsequent work. However, there are more opportunities for this to occur if others, particularly peers, are involved.

\section{IMPLICATIONS}

One reaction to many of these examples has been to think that they might be applicable to more sophisticated or advanced students only, or that they are not appropriate in programs with an intensive curriculum that needs to meet many specific outcomes. My position is that we can't afford to graduate any students who can't take responsibility for their own learning. What normally counts for employment is the fact that a person graduated, not the particular knowledge possessed. All graduates will be required to undertake considerable further learning, and be prepared often to do this at their own intiative. The university curriculum needs centrally to prepare all for this challenge.

Assessment Futures demonstrates the extensive array of ideas on which to draw, showing that assessment tasks can be selectively adapted for use in any course.
There has been a generation of discussion focusing on fine-grained features and technical requirements of assessment, but we need to balance this microscopic view with a macroscopic one that asks: what kind of learner are we.seeking to produce? Future learners will have much greater access to sources of knowledge and ways of processing it, and they will need a greater degree of executive processing skills that come with practice in dealing with complexity. This is not to suggest that an emphasis on understanding key concepts and developing key professional skills is not important, but that these must be complemented by attention to what students will do with them and how they will do it.

The dominance of the vocational move in higher education has created unrealistic expectations of "generic attributes" and "employability" skills in equipping students for immediate productive employment. Such a view, as suggested earlier, is at odds with what we know about the development of expertise-any educational process can only enable learners to progress through a few stages of development, most learning occurs through interactions in practice (Dreyfus \& Dreyfus, 2005). Moreover, the vocational view implies that possession of a limited range of attributes provides work-readiness. We need to focus on the self-regulatory skills that underpin all graduate attributes, and on the acquisition and utilisation of knowledge of all kinds.

This chapter has sketched an agenda for assessment for developing practice and illustrated it with reference to some aspects of a particular resource. Assessment has a vital role to play in developing practice, but it cannot carry the main burden. That is a function of curriculum as a whole and of the way assessment integrates with it. 1 have suggested that focusing on generic attributes, although not inappropriate, centres attention on too limited a subset of the capabilities needed for continued learning to address the range of challenges graduates will face in the world of practice. In addition a realisation is needed that learning dispositions and skills are required for any post-graduation learning, which includes the needs of the world of work. Such skills and dispositions can be developed, but a more explicit focus on them can enable all students to benefit.

\section{REFERENCES}

Biggs, J.B. (2003). Teaching for quality learning at university: What the student does, (nd ed.) Buckingham: SRHE and the Open University Press.

Black, P., \& Wilian, D. (1998). Assessment and classroom learning. Assessment in Education, 5(1), 7-74 Boud, D. (1995). Enhancing learning through self assessment. London: Kogan Page.

Boud, D. (2000). Sustainable assessment: Rethinking assessment for the learning society. Studies in Continuing Education, 22(2), 151-167.

Boud, D. (2009). How can practice reshape assessment? in G. Joughin (Ed.), Assessment, learning and judgement in higher edication (pp. 29-43). Dordrecht: Springer.

Boud, D., \& Falchikov, N. (2006). Aligning assessment with long-term learning. Assessment and Evaluation in Higher Education, 3l(4), 399-413.

Boud, D., \& Falchikov, N. (Eds.) (2007). Rethinking assessment for higher education: Learning for the longer term. London: Routledge.

Bovaird, T. (2007). Beyond engagement and participation: User and community co-production of public services. Public Administration Review, 67(5), 846-860. 
Brew, A. (2003). Teaching and research: New relationships and their implications for inquiry-based teaching and leaming in higher education. Higher Education Research and Development, 22(1), 3-18. Carless, D., Joughin, G., \& Liu, N-G. (2006). How assessment stpports learning: Learning-oriented assessment in action. Hong Kong: Hong Kong University Press.

Dreyfus, H.L., \& Dreyfus, S.E. (2005). Expertise in real world contexts. Organization Situdies, 26(5), $779-792$

Dunston, R., Lee, A., Boud, D., Brodie, P., \& Chiarella, M. (2009). Co-production and health system reform: From reimagining to remaking, Australian Journal of Public Administration, 68(1), 39-52.

Hager, P., \& Holland, S. (Eds.) (2007). Graduate attributes, learning and employability. Dordrecht: Springer.

Havnes, A., \& McDowell, L. (Eds.) (2008). Balancing dilemmas in assessment and learning in contemporary education. New York: Routledge.

Joughin, G. (Ed.) (2009). Assessment, learning and judgement in higher education. Dordrecht: Springer. Knight, P. \& Yorke, M. (2003). Assessment, learning and employability. Maidenhead: SRHE and the Open University Press.

Knight, P.T. (2002). Summative assessment in higher education: Practices in disarray. Sttrdies in Higher Education, 27(3), 275-286.

Li, L. (2001). Some refinements on peer assessinent of group projects. Assessment and Evaluation in Higher Education, $26(1), 5-18$.

Lovitts, B.E. (2005). Being a good course-taker is not enough: A theoretical perspective on the transition to independent research. Studies in Higher Education, 30(2), 137-154.

Yorke, M. (2003). Formative assessment in higher education: Moves towards theory and the enhancement of pedagogic practice. Higher Education, 45, 477-501

Zimmerman, B.J. (1990). Self-regulated learning and academic achievement: An overview. Educational Psychologist, 25, 3-17.

\section{David Boud PhD}

Faculty of Arts and Social Sciences

University of Technology, Sydney, Australia

\section{CREATING A PRACTICE-BASED LEARNING ENVIRONMENT IN THE SCIENCES}

\author{
Immersion in a Scientific Environment
}

The world is facing unprecedented challenges in the environment, has looming health problems with a burgeoning and aging human population, and has an everincreasing thirst for technology. Meeting these challenges appropriately requires the general community to understand and follow scientific debates and to engage with the issues posed by science and technology, such as the current concerns over climate change, stem cell research, water-saving strategies and geneticallymodified foods. Human population growth over the next few decades will result in even more change and uncertainty. There has never been a more important time to produce empowered science graduates and to provide students of other disciplines the opportunities to understand the nature of science and good scientific practice.

However, the number of students choosing to study science at tertiary level has declined significantly over the past two decades in many Western countries. A study commissioned by the Australian Council of Deans of Science (Dobson, 2007) revealed long-term declines in the numbers of university students studying science from 1997 to 2005 , with decreases especially evident in the fields of chemistry, physics and mathematics. This problem has been recognised in many studies, but programs to reverse such declines have largely failed (Dobson, 2003), although a small increase in science student enrolments in 2009 (perhaps owing to significant reductions in the cost of specified science courses in Australian Universities) may herald some improvement. Attrition rates of university students are also a concern, with some studies suggesting that science has one of the lowest undergraduate student completion rates of any discipline over the last decade, perhaps as low as $57 \%$ of commencing students (e.g. Martin, Maclachlan, \& Karmel, 2001) compared to a sector-wide average of around $80 \%$ (DEST, 2004)-although problems with categorising content of disciplines have yielded a more confusing picture in other studies (e.g. Long, Ferrier, \& Heagney, 2006).

There may be many reasons for the decline in numbers of science students, but most studies from countries around the world suggest that school students find the science curriculum irrelevant both to their needs and to society (e.g. Millar \& Osborne, 1998). In Australia, too, there is growing concern about the disparity between current approaches to science education and the needs and interests of our students. Goodrum, Hackling, and Rennie (2001) argued that making science more relevant to the everyday experiences of students would increase the likelihood 